\title{
Erratum to: Fragmentation of Care in Ectopic Pregnancy
}

\author{
Debra B. Stulberg ${ }^{1,2,3} \cdot$ Irma Dahlquist $^{1} \cdot$ Christina Jarosch $^{4} \cdot$ Stacy T. Lindau $^{2,3,5}$
}

Published online: 31 May 2016

(c) Springer Science+Business Media New York 2016

\section{Erratum to: Matern Child Health J (2016) \\ 20:955-961 \\ DOI 10.1007/s10995-016-1979-z}

The original version of this article unfortunately contained an error: in the "Discussion" section on page 960, the fourth line should read as "Ectopic pregnancy is a rare condition that occurs in $<2 \%$ of all pregnancies."

The online version of the original article can be found under doi:10.1007/s10995-016-1979-z.

Debra B. Stulberg

stulberg@uchicago.edu

Irma Dahlquist

ihasham@bsd.uchicago.edu

Christina Jarosch

chris.jarosch@gmail.com

Stacy T. Lindau

slindau@babies.uchicago.edu

1 Department of Family Medicine, The University of Chicago, 5841 South Maryland Avenue MC 7110, Suite M - 156, Chicago, IL 60637, USA

2 Departments of Obstetrics and Gynecology, The University of Chicago, 5841 S. Maryland Ave., MC 2050, Chicago, IL 60637, USA

3 Maclean Center for Clinical Medical Ethics, The University of Chicago, Chicago, IL, USA

4 Psychiatry Residency Program, University of Minnesota, F282/2A West, 2450 Riverside Avenue South, Minneapolis, MN 55454, USA

5 Department of Medicine - Geriatrics, The University of Chicago, Chicago, IL, USA 